\title{
Effect of social housing on the development of feeding behavior and social feeding preferences of dairy calves
}

\author{
E. K. Miller-Cushon* and T. J. DeVriest ${ }^{1}$ \\ *Department of Animal Sciences, University of Florida, Gainesville 32611 \\ †Department of Animal Biosciences, University of Guelph, Guelph, ON, N1G 2W1, Canada
}

\begin{abstract}
This study investigated how social housing affects pre- and postweaning feeding behavior and social feeding preferences of dairy calves. Twenty Holstein bull calves were housed either individually (IH; 10 calves) or in pairs (PH; 10 calves) from birth. Calves were offered grain concentrate and milk replacer ad libitum via an artificial teat ( 1 teat provided per calf) and weaned by incrementally diluting the milk replacer from 39 to $49 \mathrm{~d}$ of age. Postweaning, IH calves were paired within treatment and all pens ( $\mathrm{n}=5$ per treatment) were offered a complete pelleted diet ad libitum and followed until 13 wk of age. We recorded feeding times from video for 3 consecutive days in wk 6, 9, and 12 of age and used this to calculate daily meal frequency and meal duration. In wk 9 and 12, frequency and duration of synchronized feeding were also calculated. In addition, preference tests were conducted at time of feed delivery in wk 10 to assess the preference of each calf to feed alongside or out of visual contact of their pen mate. Pair-housed calves consumed more concentrate, in more frequent meals, than IH calves in the week before weaning (wk 6 ) and continued to have greater concentrate intake during weaning. Milk intake was not affected by treatment, but calves in $\mathrm{PH}$ pens consumed their milk in more frequent and smaller meals. Postweaning, intake was similar between treatments, but calves raised in $\mathrm{PH}$ pens continued to have meals that were more frequent and shorter in duration. Both treatments had a similar frequency of synchronized meals. However, when offered a choice to feed alone or alongside their pen mate during preference testing, calves raised in $\mathrm{PH}$ pens spent more time feeding in the presence of their pen mate than calves raised in IH pens. These results suggest that meal patterns established in response to different early social environments may persist after
\end{abstract}

Received May 26, 2015.

Accepted October 6, 2015.

${ }^{1}$ Corresponding author: tdevries@uoguelph.ca weaning and that early social contact may have longerterm effects on social feeding behavior.

Key words: dairy calf, feeding behavior, social behavior

\section{INTRODUCTION}

Recent research suggests that social housing may improve the growth and welfare of dairy calves by encouraging greater feed intake (Phillips, 2004; De Paula Vieira et al., 2010), reducing stress and supporting weight gain around weaning (Chua et al., 2002; De Paula Vieira et al., 2010), and supporting the development of normal social behavior (Veissier et al., 1994; Duve and Jensen, 2011). The presence of a social companion appears to be particularly influential when calves are managed on enhanced milk-feeding programs, which provide higher milk allowances or allow ad libitum milk intake, as social contact stimulates starter intake to a greater extent when calves are provided higher milk allowances compared with low allowances (Jensen et al., 2015). Whereas it has been well established that social housing holds potential to encourage early solid-feed intake, the influence of social contact on meal patterning in calves with free access to milk and solid feed has not been widely explored.

After weaning, it is common to house calves in groups, at which point they may encounter novel social situations and competition for feed. Much evidence shows that social contact early in life affects the development of social behavior. Previously group-housed calves have been found to respond to novel social situations with less fear and reactivity (Jensen et al., 1997; De Paula Vieira et al., 2012a) and have greater competitive success when feed access is restricted (Duve et al., 2012). This suggests that prior social contact may influence preference for social feeding and degree of social synchrony in feeding. In addition, De Paula Vieira et al. (2010) reported that calves previously housed in pairs had more frequent concentrate meals and spent more time at the feeder during 2 wk of transition to group pens with an automated feeder, suggesting that prior 
social environment may influence the ability of calves to adapt to a competitive feeding environment. It is unclear, however, whether early social housing influences the development of feeding-behavior patterns that are likely to persist over a longer period of time into the postweaning stage.

The objectives of this study were to assess the effect of preweaning social housing of dairy calves on the development and persistence of meal patterning and social feeding behavior, both before weaning and after grouping in pairs after weaning. We hypothesized that calves housed in pairs before weaning would have more frequent meals, based on the expectation that feeding would be elicited by social factors. After weaning, when all calves were housed in pairs, we hypothesized that differences in meal characteristics, such as more frequent meals in previously pair-housed calves, would persist and that calves raised in a social environment would exhibit more feeding synchrony than calves that were previously housed individually. Furthermore, we hypothesized that early social housing would influence preference for social feeding. Specifically, we predicted that calves previously raised in individual pens would prefer to feed alone, especially when feeding space was restricted, whereas calves raised in paired pens would prefer to feed with another calf.

\section{MATERIALS AND METHODS}

\section{Animals and Housing}

Twenty male Holstein calves were used in this study. Calves were purchased and transported to the University of Guelph Kemptville Campus Dairy Education and Research Centre (Kemptville, ON, Canada), where they were managed according to the standard operating procedures of the research facility, in accordance with guidelines set by the Canadian Council on Animal Care (CCAC, 2009) and as approved by the University of Guelph's Animal Care Committee (AUP\# 1913). All calves received colostrum (at least $4 \mathrm{~L}$ within the first $12 \mathrm{~h}$ of life) and arrived at the research facility within $24 \mathrm{~h}$ of birth. All calves received injections of $1 \mathrm{~mL}$ of selenium (Dystosel, Pfizer Animal Health, Kirkland, QC, Canada) and $1 \mathrm{~mL}$ of tulathromycin (Draxxin, Pfizer Animal Health) on the day they were placed on the study, as a preventive measure to reduce incidence of illness (Stanton et al., 2013). No serious illness was reported throughout the study.

\section{Milk-Feeding Procedure}

During the milk-feeding stage, calves were provided acidified milk replacer ad libitum by teat (according to the procedure outlined by Anderson, 2013). The feeding setup involved rubber teats (Peach Teats; Skellerup Industries Ltd., Woolston, New Zealand) mounted at the front of the pen and attached to tubes fitted with a oneway valve running into covered buckets placed outside the pen. All buckets, lines, and teats were cleaned daily. Calves were fed Shur-Gain Optivia Advantage Milk Replacer (Nutreco Canada Inc., Guelph, ON, Canada), containing $26 \% \mathrm{CP}$ and $16 \%$ fat. The milk replacer was mixed daily, at a rate of $150 \mathrm{~g} / \mathrm{L}$, in sufficient volume to feed all calves. At the time of preparation, a prediluted form of formic acid [The Acidified Milk Solution (9.8\% formic acid), NOD Apiary Products Ltd., Frankford, ON, Canada] was added to acidify the milk replacer to a target $\mathrm{pH}$ between 4.0 and 4.5 , to prevent microbial growth over the course of the day.

\section{Experimental Design}

The number of replicates per treatment was determined through power analysis (Morris, 1999) for those primary response variables, which had been measured in previous studies, including meal frequency and meal duration of dairy calves. Estimates of variation for these variables were based on previously reported values, obtained under similar experimental conditions (Miller-Cushon et al., 2013, 2014). It was determined that, at $80 \%$ power, biologically relevant treatment differences (e.g., differences of 2-4 meals per day) could be detected with the target sample size.

As calves were born and enrolled in the study, they were paired by age and alternately assigned to different preweaning housing treatments: (1) pair housing $(\mathbf{P H})$ or (2) individual housing (IH) in adjacent pens. Pens for PH calves were twice the size of IH pens (2.4 $\times 1.8 \mathrm{~m}$; width $\times$ depth). Pen walls were solid on 3 sides (1.3 $\mathrm{m}$ in height) with a metal gate at the front. Calves in IH pens were able to have physical and visual contact with the adjacent calf through a single window $(\sim 20 \times 20 \mathrm{~cm})$ located toward the rear of the pen but had no visual contact with other calves while feeding. Openings in the gate at the front of the pen provided access to pails for water and solid feed (pails with an 8-L capacity were used before weaning and pails with a 20-L capacity were used after weaning). The interior of each pen was bedded with wood shavings, with bedding replaced weekly and fresh bedding added as needed. Calf pens were located under a 3 -sided, roofed shelter, with the front of the pen facing the open side of the shelter to allow for natural ventilation while protecting the pens from rain. Calves in $\mathrm{PH}$ pens had access to milk via 2 teats (placed $50 \mathrm{~cm}$ apart in the center of the pen) and 2 feed buckets, whereas calves in IH pens 
had a single teat and feed bucket. Water was available ad libitum in additional buckets.

Fresh milk replacer was provided daily at $0800 \mathrm{~h}$, with the amount replenished at $1600 \mathrm{~h}$ as required to ensure unrestricted intake in all pens. Fresh grain concentrate (Table 1) was delivered daily at $1000 \mathrm{~h}$ in quantities to ensure ad libitum intake. Calves were weaned from milk replacer during d 39 to 49 of age by incrementally diluting the milk replacer: $112.5 \mathrm{~g}$ of $\mathrm{DM} / \mathrm{L}$ on d 40 to $42,75 \mathrm{~g}$ of $\mathrm{DM} / \mathrm{L}$ on d 43 to $44,37.5 \mathrm{~g}$ of $\mathrm{DM} / \mathrm{L}$ on d 46 to 48 , and water offered on d 49 .

On the first day after weaning (d 50 of age), calves reared individually were paired within treatment, by removing the wall between adjacent IH pens. Calves were followed for $5 \mathrm{wk}$ after weaning, during which all pairs of calves were managed identically. On the first day of wk 8 , all pens were offered a complete pelleted diet (Table 1) ad libitum in place of concentrate.

\section{Intake and Growth Measurements}

We recorded the intake of solid feed (and milk during the milk-feeding stage) daily at the pen level, based on offered and refused quantities of feed. Calves were weighed at the same time on the first $2 \mathrm{~d}$ each week, with repeated measurements made to obtain a representative weekly weight.

\section{Feed Sampling and Analysis}

For determination of the DM and nutrient content of the feed and assessment of daily DMI of the calves, fresh feed and orts were sampled weekly, just before removal and delivery of fresh feed. This sampling protocol was consistent throughout the study; however, the samples taken changed from concentrate during the milk-feeding stage to the complete pelleted diet in wk 8. All samples were immediately frozen at $-20^{\circ} \mathrm{C}$ until they were further analyzed.

Samples taken for DM and chemical analysis were oven dried at $55^{\circ} \mathrm{C}$ for $48 \mathrm{~h}$ to determine DM content. Fresh samples taken for chemical analysis were ground to pass through a 1-mm screen (Wiley Mill, Arthur H. Thomas Co., Philadelphia, PA). These samples were then pooled by 2 -wk time interval ( 3 samples from the milk-feeding stage and 3 from the postweaning stage) and sent to Cumberland Valley Analytical Services Inc. (Maugansville, MD) for analysis of DM $\left(135^{\circ} \mathrm{C}\right.$; AOAC International, 2000: method 930.15), ash $\left(535^{\circ} \mathrm{C}\right.$; AOAC International, 2000: method 942.05), ADF (AOAC International, 2000: method 973.18), NDF with heatstable $\alpha$-amylase and sodium sulfite (Van Soest et al.,
Table 1. Chemical composition of feeds (mean \pm SD; DM basis)

\begin{tabular}{lll}
\hline $\begin{array}{l}\text { Chemical } \\
\text { composition }\end{array}$ & Concentrate & \\
\hline DM (\%) & Pelleted diet \\
CP (\% of DM) & $87.8 \pm 0.40$ & $91.6 \pm 1.70$ \\
ADF (\% of DM) & $22.6 \pm 1.24$ & $21.1 \pm 0.14$ \\
NDF (\% of DM) & $8.08 \pm 0.93$ & $18.2 \pm 0.50$ \\
NFC (\% of DM) & $16.4 \pm 0.66$ & $35.7 \pm 1.58$ \\
ME (Mcal/kg of DM) & $47.7 \pm 2.00$ & $30.8 \pm 1.49$ \\
Fat (\% of DM) & $2.89 \pm 0.016$ & $2.49 \pm 0.018$ \\
\end{tabular}

${ }^{1}$ Values were obtained from chemical analysis of feed samples. NFC $=100-(\% \mathrm{CP}+\% \mathrm{NDF}+\%$ fat $+\%$ ash $) . \mathrm{ME}=$ total digestible nutrients $(\mathrm{TDN}) \times 0.04409 \times 0.82$ (calculated according to NRC, 2001, equations).

${ }^{2}$ Supplied by Rooney's Feeds (Iroquois, ON, Canada), containing (on as-is basis) $36.5 \%$ corn, $28 \%$ calf starter supplement supplied by ShurGain (Nutreco Canada Inc., Guelph, ON, Canada), $20 \%$ rolled barley, $10 \%$ rolled oats, $2.5 \%$ dilute monensin sodium, $2 \%$ molasses, and $1 \%$ soybean oil.

${ }^{3}$ Shur-gain High Fiber 20\% Dairy Heifer Ration (Nutreco Canada Inc.).

1991), and $\mathrm{CP}(\mathrm{N} \times 6.25$; AOAC International, 2000: method 990.03; Leco FP-528 Nitrogen Analyzer, Leco, St. Joseph, MI).

\section{Feeding Behavior}

The behavior of all calves was recorded using 8 color video cameras (Day/Night Camera, model no. WV-CP504; Panasonic, Osaka, Japan) fitted with an F0.95/2.8- to 8-mm lens (Fujinon CCTV lens, Fuji, Tokyo, Japan). The cameras were connected to a digital video recorder (Digital Disk Recorder, model no. WJHD616K, Panasonic) set to record at 15 images per second and positioned above the pens such that each pen was fully visible from one of the cameras (placed $\sim 2 \mathrm{~m}$ in front of the pens and $4 \mathrm{~m}$ from the pen floor). Four red lights $(100 \mathrm{~W})$ were spaced evenly between the cameras and placed on a timer to provide enough light to record during nighttime hours (on from 1900 to $0700 \mathrm{~h}$ ).

During the milk-feeding stage, we observed calves within pens individually for $3 \mathrm{~d}$ at the beginning of wk 6 . Instantaneous scans were performed at intervals of $30 \mathrm{~s}$ (as validated by Miller-Cushon and DeVries, 2011) to record milk feeding (defined as taking place when a calf mouth was closed on a teat) and concentrate feeding (defined as taking place when a calf head was lowered in the feed bucket). Competitive behavior occurring when pair-housed calves were drinking milk was assessed by recording instances of displacements (one calf butts or pushes the other calf away from the teat and replaces them at that feeding station, as defined by von Keyserlingk et al., 2004). 
During the postweaning stage, we observed calves within pens individually for $3 \mathrm{~d}$ at the beginning of wk 9 and 12. Instantaneous scans were performed at intervals of $60 \mathrm{~s}$ to record feeding (as validated for postweaning feeding behavior by Miller-Cushon and DeVries, 2011). Competitive behavior at feed buckets was assessed by recording instances of displacements (one calf butts or pushes the other calf away from the bucket and replaces them).

Meal criteria were determined as described by DeVries et al. (2003) using a software package (MIX 3.1.3; MacDonald and Green, 1988). Meal analysis was performed on feeding data collected for individual calves. For this analysis, meal criteria (the minimum duration of a time interval between meals) were determined for the milk-feeding stage (with meal criteria determined for both milk-feeding and solid-feed data) and for separate weeks of the postweaning stage. Meal criteria were calculated for individual calves within week for milk meals and postweaning meals; however, short feeding times before weaning provided insufficient data to perform this analysis for the solid-feed meals of individual calves. Thus, data were pooled by treatment for calculation of preweaning solid-feed meal criteria. Preweaning solid-feed meal criteria were 16.7 and 10.5 min for IH and PH calves, respectively (determined from data pooled by treatment). Milk meal criteria were
$17.2 \pm 4.6$ min $($ mean $\pm \mathrm{SD})$ and $17.9 \pm 4.4$ min for $\mathrm{IH}$ and $\mathrm{PH}$ calves, respectively (determined for individual calves). Postweaning mean solid-feed meal criteria were $16.7 \pm 3.2$ and $17.4 \pm 3.7$ min for previously $\mathrm{IH}$ and $\mathrm{PH}$ calves, respectively (determined for individual calves in both observation weeks).

According to meal criteria, the start and end times of individual meals for each calf in each day were identified, and meal frequencies and durations were determined. Rate of intake was calculated at the pen level as daily intake divided by total feeding time. Once all calves were housed in pairs postweaning, we assessed synchrony of feeding as both the daily duration of time that calves within a pen were engaged in simultaneous meals (with meals defined according to individual meal criteria) and the daily frequency of synchronized meals (the number of meals that included simultaneous meal time).

\section{Preference Test}

To evaluate preference of calves for feeding and standing in the presence of another calf, 2 tests were conducted over the course of an 8-d period beginning at d 63 of age. Preference tests were conducted using a modified Y-maze in the home pen of the calves $(2.4 \times$ $1.8 \mathrm{~m}$; width $\times$ depth), illustrated in Figure 1 . a)

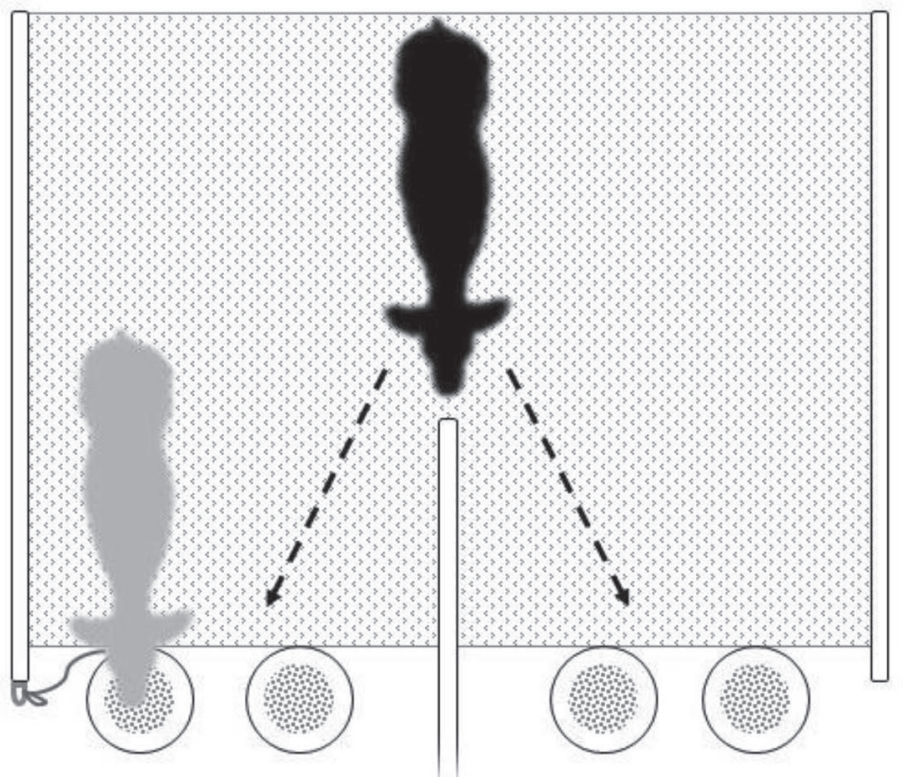

b)

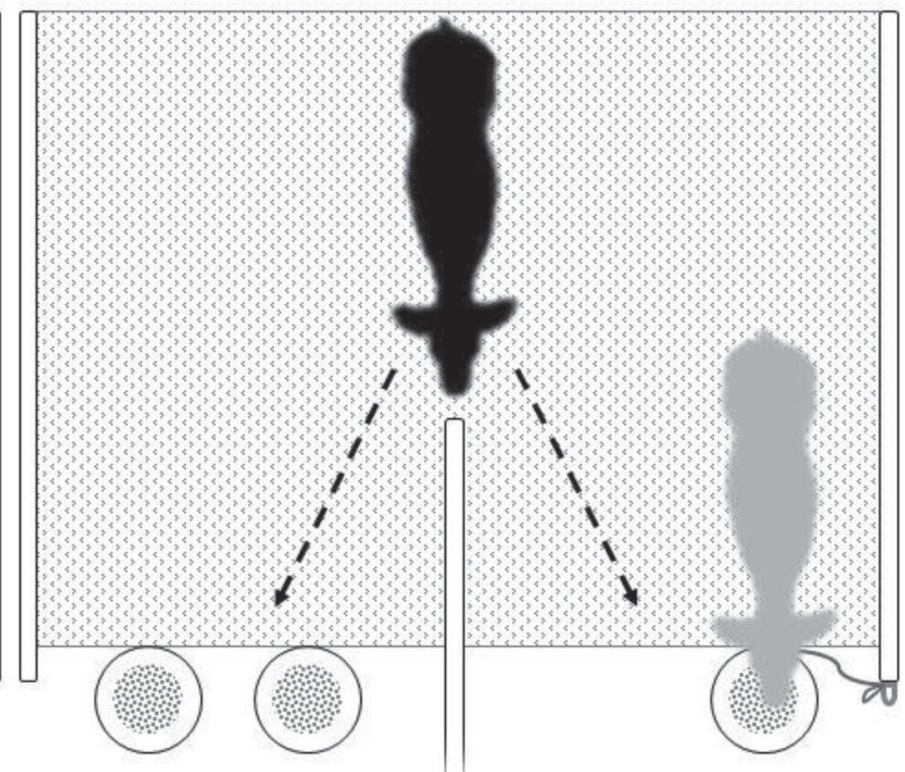

Figure 1. Diagram of pen arrangement for (a) preference test 1 (noncompetitive feeding on social side of pen) and (b) preference test 2 (competitive feeding on social side of pen). The test calf is shown in black and the tethered nontest calf is shown in gray. The side on which the nontest calf was tethered (social side) was randomly assigned and alternated (left or right) between tests. Both calves in each pen were tested on consecutive days. Dimensions of the pen were $2.4 \times 1.8 \mathrm{~m}$ (width $\times$ depth), and the calf was approximately $1 \mathrm{~m}$ from feed buckets on either side. 
During the preference test, the nontest calf was loosely tethered with a rope halter on one side of the pen and a wall was placed in the pen to partially divide it into 2 areas: a social side and an isolated side. On the social side of the pen, the test calf had room to stand beside the tethered pen mate. On the isolated side of the pen, the test calf had no visual or physical contact with the pen mate while feeding. One feed bucket was always placed on the isolated side of the pen, one bucket was always placed directly in front of the tethered calf, and additional buckets were placed as needed for each test. In preference test 1 , the test calf was offered a choice of either noncompetitive social feeding or isolated feeding (Figure 1a). For this test, the side of the pen with the tethered calf (the social side) had 2 feed buckets such that the test calf could feed alongside the nontest calf, but the nontest calf could not reach to displace the test calf. In preference test 2, the test calf was offered a choice of social feeding with restricted feeding places (designed to create a more competitive feeding environment) or isolated feeding (Figure 1b). For this test, the side of the pen with the tethered calf had 1 feed bucket, such that the test calf had to replace the nontest calf (potentially competitively) to feed on that side.

Preference tests were conducted at time of feed delivery $(1000 \mathrm{~h})$. Immediately before the start of the test, the nontest calf was tethered and the test calf was held at the back of the pen. At the start of the test, refilled feed buckets were placed in the pen and the test calf was released and able to choose on which side of the pen to feed. Movement of the test calf was not restricted. The test concluded after $60 \mathrm{~min}$ had passed or when the test calf lay down. Calves in each pen were tested on alternating days during the 8-d testing period, such that each calf was tested a total of 4 times (twice for preference test 1 and twice for preference test 2 ). The side of the pen (right or left) where the nontest calf was tethered was alternated between tests, such that data for each calf and test were averaged across 2 tests conducted on different sides of the pen.

Video recordings were used to collect behavioral data during the test. We used continuous recording to determine initial side choice and time and location of feeding and standing. If the calf stood at the dividing point of the pen, with no clear orientation toward one side, that time was recorded and excluded from analysis.

\section{Statistical Analyses}

Data were analyzed separately by stage: preweaning, weaning, and postweaning. Throughout the study, data were analyzed at the pen level. When data were collected for individual calves, they were averaged across pen (i.e., for IH calves before weaning, data were averaged across adjacent calves). Intake data were averaged across calves in the pen to yield average intake per calf for analysis. All data were averaged by week, except for weaning data, which were averaged across the 10 -d weaning period. Feeding-behavior data obtained for individual calves from video analysis were averaged by pen (or adjacent IH calves) across the $3 \mathrm{~d}$ in each observation week (wk 6 before weaning, and wk 9 and 12 after weaning).

To examine the effect of treatment on intake, growth (ADG), and feeding behavior, data were analyzed using the MIXED procedure of SAS (SAS v.9.4, SAS Institute Inc., 2012), treating week as a repeated measure when data spanned multiple weeks. The model included the fixed effects of week, treatment, and week $\times$ treatment interaction and the random effect of pen. For analysis of intake and growth, the model included initial BW as a covariate. For preweaning and postweaning intake and growth data, the autoregressive model was selected as the variance-covariance matrix structure on the basis of best fit according to Schwarz's Bayesian information criterion. For postweaning feeding-behavior data, compound symmetry was selected. Competitive interactions were very infrequent, and so only numerical results are reported.

Preference-test data were analyzed separately for test 1 and test 2. Duration of time spent feeding on the social side of the pen was calculated as a percentage of total feeding time during the test, and the duration of time spent standing on the social side was calculated as a percentage of total test time. These data were averaged across pen. The frequency of switching sides was summarized by pen and test. To assess initial side choice, the percentage of tests where the test calf moved to the social side first was calculated at the pen level. These data were analyzed using the MIXED procedure of SAS in a model that included the fixed effect of treatment and the random effect of pen.

For all analyses, preliminary screening of the data (using UNIVARIATE procedure of SAS) revealed that dependent variables were normally distributed. All values reported are least squares means. Significance was declared at $P \leq 0.05$, and trends were reported if 0.05 $<P \leq 0.10$.

\section{RESULTS}

Social housing influenced solid-feed intake during the milk-feeding stage, with concentrate intake subject to a treatment $\times$ week interaction (Table 2), increasing to a greater extent over time in $\mathrm{PH}$ calves compared with IH calves, as shown in Figure 2. Concentrate intake of 


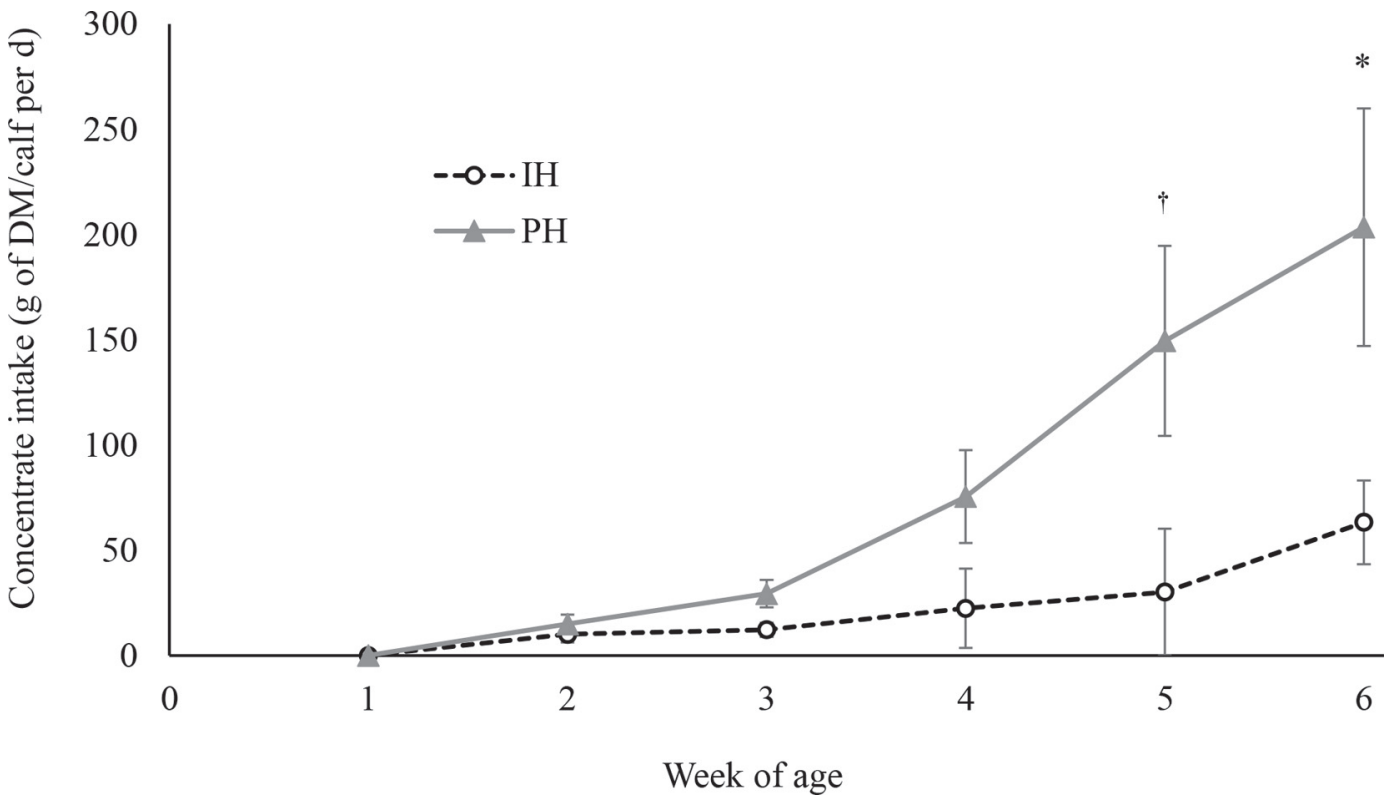

Figure 2. Concentrate intake over the preweaning period of calves housed individually (IH) or in pairs (PH). Values are averaged across calves in a pen, week of age, and treatment. Error bars represent standard error. Differences between treatments by week denoted as $* P<0.05$, $\dagger P<0.1$

PH calves tended $(P=0.06)$ to be greater than that of $\mathrm{IH}$ calves in wk 5 and was greater in wk 6 . During the weaning period, $\mathrm{PH}$ calves consumed more solid feed and had greater ADG (Table 2). Milk intake and ADG were similar before weaning.

Meal characteristics during the milk-feeding period differed between treatments (Table 3). When feeding behavior was assessed in wk 6 of life, rate of intake, meal duration, and meal size were similar between treatments. However, calves in $\mathrm{PH}$ pens had more frequent solid-feed meals and, consequently, greater DMI. Preweaning solid-feed meal criteria (determined from data pooled by treatment) were 16.7 and $10.5 \mathrm{~min}$ for $\mathrm{IH}$ and $\mathrm{PH}$ calves, respectively. The numerical differ-

Table 2. Intakes and growth performance before, during, and after weaning of calves housed individually (IH) or in pairs $(\mathrm{PH})$ during the milk-feeding stage ${ }^{1}$

\begin{tabular}{|c|c|c|c|c|c|c|}
\hline \multirow[b]{2}{*}{ Item } & \multicolumn{2}{|c|}{ Treatment $(\mathrm{T})$} & \multirow[b]{2}{*}{$\mathrm{SE}$} & \multicolumn{3}{|c|}{$P$-value ${ }^{2}$} \\
\hline & $\mathrm{IH}$ & $\mathrm{PH}$ & & $\mathrm{T}^{3}$ & $\mathrm{~W}^{4}$ & $\mathrm{~T} \times \mathrm{W}^{4}$ \\
\hline \multicolumn{7}{|l|}{ Before weaning } \\
\hline $\mathrm{MR}^{5}$ intake $(\mathrm{L} / \mathrm{d})$ & 9.8 & 9.8 & 0.82 & 0.99 & $<0.001$ & 0.96 \\
\hline Feed DMI $(\mathrm{kg} / \mathrm{d})$ & 0.023 & 0.079 & 0.022 & 0.11 & $<0.001$ & 0.013 \\
\hline $\mathrm{ADG}(\mathrm{kg} / \mathrm{d})$ & 1.1 & 1.0 & 0.10 & 0.45 & 0.054 & 0.84 \\
\hline \multicolumn{7}{|l|}{ Weaning } \\
\hline Feed DMI (kg/d) & 0.20 & 0.46 & 0.078 & 0.038 & - & - \\
\hline $\mathrm{ADG}(\mathrm{kg} / \mathrm{d})$ & 0.41 & 0.67 & 0.066 & 0.024 & - & - \\
\hline \multicolumn{7}{|l|}{ After weaning } \\
\hline DMI $(\mathrm{kg} / \mathrm{d})$ & 3.4 & 3.2 & 0.15 & 0.62 & $<0.001$ & 0.70 \\
\hline $\mathrm{ADG}(\mathrm{kg} / \mathrm{d})$ & 1.3 & 1.1 & 0.070 & 0.15 & 0.56 & 0.48 \\
\hline
\end{tabular}

${ }^{1}$ Data are averaged across calves within a paired pen or across calves in adjacent individual pens $(\mathrm{n}=5$ per treatment). Intake of pair-housed calves was measured at the pen level and divided by 2 for analysis.

${ }^{2} \mathrm{~T}=$ treatment $(\mathrm{IH}=$ calves housed individually until $\mathrm{d} 50 ; \mathrm{PH}=$ calves housed in pairs until $\mathrm{d} 50) ; \mathrm{W}=$ week on treatment [preweaning $=$ wk 1-6 (d 39); weaning $=\mathrm{d} 39-49$; postweaning $=$ wk 8-12].

${ }^{3}$ Degrees of freedom were $\mathrm{df}($ effects $)=1, \mathrm{df}($ error $)=8$.

${ }^{4}$ Degrees of freedom were $\mathrm{df}($ effects $)=5, \mathrm{df}($ error $)=40$ for preweaning stage, and $\mathrm{df}($ effects $)=4$, $\mathrm{df}($ error $)=$ 32 for postweaning stage.

${ }^{5} \mathrm{MR}=$ milk replacer. 
Table 3. Solid-feed and milk meal characteristics of calves housed individually (IH) or in pairs (PH) in wk 6 of life ${ }^{1}$

\begin{tabular}{lcccc}
\hline & \multicolumn{2}{c}{ Treatment } & & \\
\cline { 2 - 3 } Item & $\mathrm{IH}$ & $\mathrm{PH}$ & $\mathrm{SE}$ & -value $^{2}$ \\
\hline Solid-feed meals & & & & \\
DMI (kg/d) & 0.062 & 0.17 & 0.030 & 0.038 \\
Meal frequency (meals/d) & 4.6 & 8.0 & 0.89 & 0.025 \\
Meal duration (min) & 2.7 & 3.8 & 0.89 & 0.42 \\
Rate of intake (g/min) & 11.3 & 15.4 & 3.2 & 0.34 \\
Intake per meal (g) & 15.6 & 23.6 & 4.0 & 0.20 \\
Milk-replacer meals & 12.1 & 11.8 & 0.87 & 0.81 \\
Intake (L/d) & 4.6 & 7.1 & 0.55 & 0.016 \\
Meal frequency (meals/d) & 8.1 & 7.1 & 0.64 & 0.32 \\
Meal duration (min) & 0.40 & 0.38 & 0.036 & 0.75 \\
Rate of intake (L/min) & 2.8 & 1.6 & 0.32 & 0.048 \\
Intake per meal (L) & & & & \\
\hline
\end{tabular}

${ }^{1}$ Data are averaged across $3 \mathrm{~d}$ of observation (d 36-38 of life for each calf). Meal characteristic data, measured from video for individual calves, are averaged across calves within a paired pen or across calves in adjacent individual pens $(\mathrm{n}=5 /$ treatment). Intake of pair-housed calves was measured at the pen level and divided by 2 for analysis.

${ }^{2}$ Degrees of freedom for all analysis were $\mathrm{df}($ effects $)=1, \mathrm{df}($ error $)=8$.

ence $(6.2 \mathrm{~min})$ in the best-fit bout criteria for different treatments had a negligible effect on how the feeding data were parsed into meals. Only 2 examples existed in the data (across all calves and days) where a meal would have been divided into 2 had the shorter meal criteria been used. As such, differences in meal frequency between treatments were not a result of different meal criteria.

Although milk intake, in comparison with solid-feed intake, was not affected by treatment in wk 6 of life, milk meal characteristics also differed between treatments, with calves in $\mathrm{PH}$ pens having more frequent, smaller meals of milk (Table 3). Duration of milk meals and rate of milk intake were similar between treatments. The milk meal criteria (calculated for individual calves) was $17.6 \pm 2.5$ (mean $\pm \mathrm{SD}$ ) and did not differ by treatment $\left(F_{1,8}=0.18, P=0.69\right)$. Competitive interactions were observed occasionally $(1.3 \pm 1.1$ displacements per day) in $\mathrm{PH}$ pens during wk 6 .

After weaning, once IH calves were paired within treatment, previous social housing had no effect on DMI or ADG for the remainder of the study period (Table 2), and final BW did not differ between treatments $\left(126.4\right.$ vs. 119.8 , IH vs. $\mathrm{PH} ; \mathrm{SE}=6.3, F_{1,8}=$ $0.56, P=0.48)$. However, feeding behavior did differ in the postweaning period. Total daily time spent feeding was similar between treatments, but calves previously housed in $\mathrm{PH}$ pens had more frequent meals that were shorter in duration, compared with calves reared IH before weaning. Effects of previous housing on meal characteristics persisted between observations in wk 9 (one week after weaning) and wk 12 . Independent of treatment, meal duration and total daily meal time decreased over time, whereas meal frequency increased. The frequency of synchronized meals in the postweaning stage was similar between calves previously housed $\mathrm{IH}$ and $\mathrm{PH}$ (Table 4), and the daily duration of synchronized meal time tended to be lower for $\mathrm{PH}$ calves. The postweaning meal criteria (calculated for individual calves) was $17.1 \pm 3.1$ min (mean $\pm \mathrm{SD}$ ) and did not differ by treatment $\left(F_{1,8}=0.21, P=0.66\right)$. Competitive interactions in the postweaning period were very rare, with a single recording of a displacement in a pen of calves that were previously housed IH, and 2 instances of displacements in a $\mathrm{PH}$ pen.

Results of the preference tests for social activity are shown in Figure 3. During the first preference test, when calves were offered a choice of social noncompetitive feeding ( 2 buckets on the side with the tethered calf) or isolated feeding, calves previously housed $\mathrm{PH}$ preferred to feed on the social side $\left(\mathrm{t}_{4}=5.47 ; P=\right.$ $0.005)$ and calves previously housed IH tended to prefer to feed on the social side $\left(\mathrm{t}_{4}=2.53 ; P=0.06\right)$. The calves that were previously housed $\mathrm{PH}$ spent a greater percentage of feeding time on the social side of the pen than IH calves $\left(F_{1.8}=10.70 ; P=0.011\right)$. Similar results were seen during the second preference test when calves were offered a choice of social feeding with restricted feeding places (1 bucket on the side with the tethered calf) or isolated feeding. Calves previously housed $\mathrm{PH}$ maintained a preference for feeding on the social side $\left(\mathrm{t}_{4}=7.89 ; P=0.001\right)$, whereas calves previously housed IH tended to prefer feeding on the social side $\left(\mathrm{t}_{4}=2.23 ; P=0.09\right)$, and calves previously housed $\mathrm{PH}$ spent a greater percentage of feeding time on the social side than calves previously housed IH $\left(F_{1,8}=7.72 ; P=\right.$ 
Table 4. Postweaning meal characteristics and social feeding data for pair-housed calves that were previously housed individually (IH) or in pairs $(\mathrm{PH})$ during the milk-feeding stage ${ }^{1}$

\begin{tabular}{|c|c|c|c|c|c|c|c|c|}
\hline \multirow[b]{2}{*}{ Item } & \multicolumn{2}{|c|}{ Previously IH } & \multicolumn{2}{|c|}{ Previously PH } & \multirow[b]{2}{*}{$\mathrm{SE}$} & \multicolumn{3}{|c|}{$P$-value ${ }^{2,3}$} \\
\hline & wk 9 & wk 12 & wk 9 & wk 12 & & $\mathrm{~T}$ & $\mathrm{~W}$ & $\mathrm{~T} \times \mathrm{W}$ \\
\hline Meal time $(\min / \mathrm{d})$ & 231.6 & 170.1 & 214.6 & 154.8 & 15.4 & 0.43 & $<0.001$ & 0.93 \\
\hline Meal frequency (meals/d) & 12.8 & 13.7 & 14.3 & 16.3 & 0.67 & 0.044 & 0.017 & 0.19 \\
\hline Meal duration (min) & 18.5 & 12.6 & 15.0 & 9.5 & 0.89 & 0.0053 & $<0.001$ & 0.83 \\
\hline Synchronized meal time ${ }^{4}(\min / \mathrm{d})$ & 116.5 & 60.1 & 77.6 & 40.6 & 11.0 & 0.053 & $<0.001$ & 0.29 \\
\hline
\end{tabular}

${ }^{1}$ Data are averaged across 3 d of observation per week (wk 9: d 57-59; and wk 12: d 78-80) for 5 pens per treatment.

${ }^{2} \mathrm{~T}=$ treatment $(\mathrm{IH}=$ previously housed individually during the milk-feeding stage, $\mathrm{PH}=$ previously housed in pairs during the milk-feeding stage; $\mathrm{W}=$ week.

${ }^{3}$ Degrees of freedom for all analyses were $\mathrm{df}($ effects $)=1$, $\mathrm{df}$ (error) $=8$.

${ }^{4}$ Synchrony of meals calculated within pen according to meal criteria for milk meals of individual calves.

0.024). In both tests, previous housing treatment had no effect $(P>0.62)$ on the percentage of time calves spent standing on either the social side or the isolated side, and calves exhibited no preference $(P>0.27)$ for spending time on either side. However, previous housing treatment had some effects on the initial side choice and the number of times calves switched between sides. In the first preference test, housing treatment did not affect the percentage of times that the social side was chosen initially (63 vs. $40 \%$ for previously $\mathrm{PH}$ vs. IH; $\left.\mathrm{SE}=12.0, F_{1,8}=1.70 ; P=0.23\right)$, but calves previously housed $\mathrm{PH}$ tended to switch sides more frequently $(7.3$ vs. 4.9 times during the test; $\mathrm{SE}=0.84 ; F_{1.8}=4.07 ; P=$
0.08). During the second test, calves previously housed $\mathrm{PH}$ initially chose the social side during a greater percentage of tests than IH ( 85 vs. $53 \%, F_{1,8}=9.02 ; \mathrm{SE}$ $=7.5 ; P=0.017)$ but switched sides a similar number of times (5.2 vs. 6.4 times; $\mathrm{SE}=1.1 ; F_{1.8}=0.66 ; P=$ $0.44)$.

\section{DISCUSSION}

It is commonly reported that group-housed calves consume more solid feed before weaning than calves housed individually (Phillips, 2004; De Paula Vieira et al., 2010). In the present study, social housing increased a)

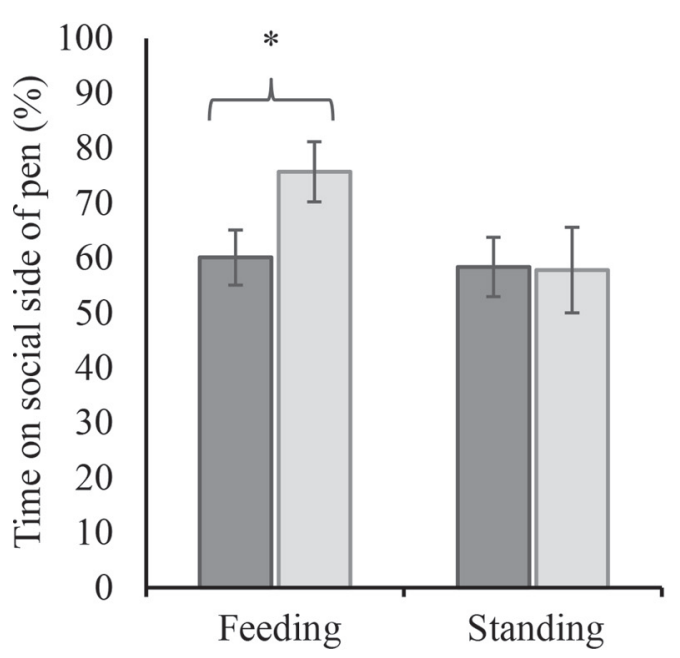

b)

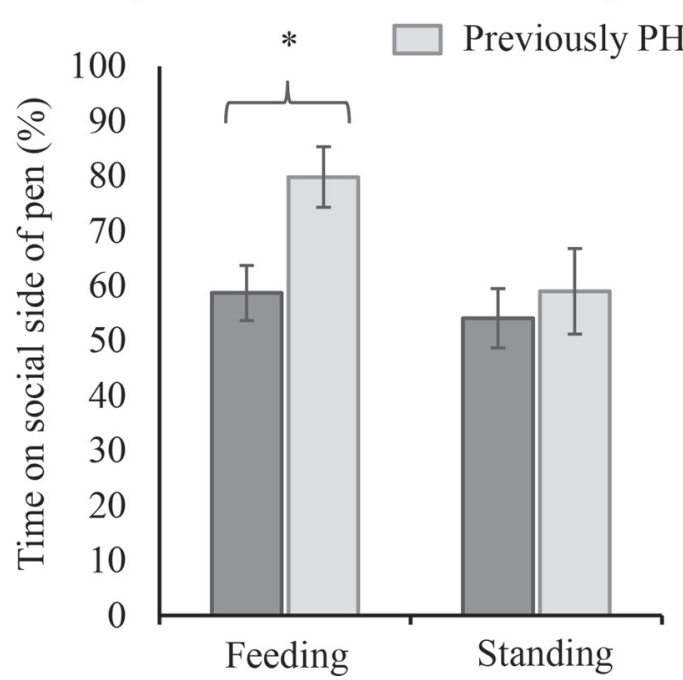

Figure 3. Preference of pair-housed calves previously reared individually (IH) or in pairs ( $\mathrm{PH}$ ) for feeding and standing in the presence of a social companion. Calves were offered a choice of feeding with a visual and physical barrier between them and their pen mate or feeding alongside the tethered pen mate, when (a) social feeding was noncompetitive (2 buckets on social side of pen) and (b) social feeding was competitive (1 feed bucket on social side of pen). Data for each preference test are averaged across calf ( 2 tests per calf $)$ and pen $(\mathrm{n}=5$ pens per treatment). Error bars indicate standard error of the mean. ${ }^{*} P<0.05$. 
solid-feed intake in the later weeks of the milk-feeding stage and through weaning, without affecting milk intake. As we predicted, social housing influenced both milk and solid meal patterns, encouraging more frequent meals in pair-housed calves. Interestingly, whereas more frequent concentrate meals corresponded with greater DMI in pair-housed calves, differences in milk meal characteristics did not correspond with differences in daily milk intake, with pair-housed calves regulating their daily intake through reducing the amount of milk consumed during their meals. Consistent with previous results (De Paula Vieira et al., 2010), an increase in solid-feed intake through weaning corresponded with greater ADG during this period. These results contribute to a body of evidence suggesting that social housing is particularly beneficial in intensified milk-feeding systems, to aid in encouraging early solid-feed intake and supporting a smooth transition at weaning (Jensen et al., 2015).

Social influences on the development of feeding behavior in young ruminants are extensive, with feed preferences and foraging decisions highly subject to the behavior of other animals in the group (Galef and Laland, 2005; Launchbaugh and Howery, 2005). Social stimuli can act to directly elicit a behavior, as in social facilitation, or indirectly, as in local or stimulus enhancement (Nicol, 1995). The effects of pair housing on meal frequency may, thus, be explained by social influences on feeding behavior and social learning. Increased feed intake in group-housed animals has often been attributed to the social facilitation of feeding in calves (Phillips, 2004; De Paula Vieira et al., 2010) and adult cattle (Albright, 1993). Through social facilitation, a calf may be more likely to approach the feeder when another calf is feeding. Synchronized behavior is commonly observed in calves (Duve and Jensen, 2012; Miller-Cushon et al., 2014), offering further evidence that feeding behavior is socially facilitated. Feeding choices are also subject to local enhancement, through which the behavior of one animal draws the attention of another toward a particular food source (Nicol, 1995). Local enhancement was described as a potential factor affecting behavior of group-housed calves by De Paula Vieira et al. (2012b), who reported that calves housed with a weaned companion had more frequent visits to hay and concentrate feeders than calves housed in groups of similar age. Although it is clear that social learning plays an important role in the learning of feeding behavior in calves, it is difficult to assess which specific learning mechanisms are at work. The present results suggest that social influences on feeding behavior require either full contact with another calf or visual contact with a feeding calf, as opposed to the limited contact that was provided to individually housed calves (windows at the back of the pen).

It should be noted that other factors in the pairhousing environment in the present study may have influenced feeding patterns. For example, although the space provided per calf was held constant across treatments, pair-housed calves had more total area to move in and may have been more active. Although standing and lying time were not recorded in the present study, Chua et al. (2002) reported that pair-housed calves, managed in a similar housing environment to the present study, were more active than individually housed calves. It is possible that increased activity may have influenced feeding frequency. In addition, we designed the present experiment to provide a constant ratio of feeding places to calf number across treatments (i.e., one bucket or teat per calf in the pen); however, this meant that pair-housed calves had access to a total of 2 feed buckets and teats. It is possible that more numerous feeding places encouraged more frequent meals. Further research to address this possibility is encouraged.

Once all calves were paired within treatment after weaning, intake and ADG were not affected by treatment. However, meal characteristics persistently differed, with previously pair-housed calves continuing to have more frequent, smaller solid-feed meals. Differences in behavior arising from early social housing were maintained at the conclusion of the study, after both treatments had been managed similarly in pairs for $5 \mathrm{wk}$. These data are relatively unique, as many previous studies have concluded at time of weaning or within 2 wk of weaning. For instance, De Paula Vieira et al. (2010) recorded differences in feeding behavior after weaning upon mixing in a group of 6 calves, and reported that calves raised in pairs had shorter latencies to access the feeder, more frequent meals, and consumed more solid feed during the 2 wk after mixing, compared with calves previously housed individually. Calves in that study were presented after weaning with both a novel feeding method (they had to learn to use an automated feeder) and a novel social environment. De Paula Vieira et al. (2010) speculated that the effects of early social contact on the response to mixing could be due to differences in social or cognitive development, and overall ability to cope with competitive pressure. In comparison, the present study demonstrates that feeding patterns acquired early in life may be carried through weaning and persist for some time. This suggests that conducting longer-term studies has merit to assess the potential for early behavioral development of the calf to influence the expression of behavior over longer periods of time, and potentially into lactation. 
Several factors may have contributed to the postweaning differences in feeding behavior. We had hypothesized that social influences on feeding behavior may be greater in previously pair-housed calves, with more frequent meals potentially explained by a greater degree of social facilitation. However, the frequency of synchronized meals was similar between treatments after weaning. In fact, the total daily duration of synchronized meal time tended to be longer in calves previously housed individually, likely because those calves had meals that were longer in duration, on average. Similar feeding synchrony does not preclude other effects of social learning on postweaning feeding behavior. Differences in response to social cues may offer an explanation for greater meal frequency, if calves raised in pairs were more likely to approach the feed bucket after observing their pen mate consume a meal (local enhancement).

It is also interesting to note that the pattern of consuming feed in larger and less frequent meals exhibited by the calves raised individually is what we might have expected if they were experiencing competitive pressure. Reducing available feeding locations has been widely reported to decrease meal frequency in calves (von Keyserlingk et al., 2004; Miller-Cushon et al., 2014), heifers (DeVries and von Keyserlingk, 2009), and adult cows (Proudfoot et al., 2009). Although displacements at the feed bucket were very rare in both treatments, it could be speculated that calves raised individually found social feeding stressful and so responded by consuming larger and less frequent meals. Differences in social bonding between calves raised in pairs from birth and calves that only had limited prior social contact with their neighbor may also have contributed to postweaning differences in behavior. Evidence suggests that calves prefer to be with a familiar calf rather than an unfamiliar one (Færevik et al., 2007) and that calves raised individually are more fearful and less explorative, at least in a novel environment (Jensen et al., 1997). It is also possible that the age of introduction to social contact may be influential in the development of social bonding and behavior. Costa et al. (2015) reported that the influence of social contact on solid-feed intake was greatest when calves were housed pair housed within the first week of life, rather than just before or after weaning. In further work, examining the persistence of behavioral differences in calves regrouped with unfamiliar pen mates would shed light on the relative effects of early social contact compared with social bonding with a specific pen mate on longer-term differences in feeding behavior.

Although the degree of feeding synchrony was not greatly affected by treatment, results of the social feeding preference test suggest that preweaning social housing had effects on postweaning preference for social feeding. We designed the preference test to assess whether calves prefer to feed individually or in the presence of a social companion, and whether this preference depends on prior social experiences and the degree of competition for access to food. Whereas previously individually housed calves did not exhibit an initial side preference in either test, calves previously housed in pairs exhibited an initial preference for social feeding in test 2 . In test 1 , a lack of an initial side preference corresponded with increased switching between sides in previously pair-housed calves, suggesting that the total time spent feeding on the social side of the pen may provide the clearest insight into preference for social feeding. Those results generally suggest that calves reared with social contact before weaning have a stronger preference for social feeding. Greater time spent feeding in the presence of the nontest calf may mean that calves raised in pairs were more responsive to social cues, or simply more comfortable (or less fearful) feeding alongside another calf. However, calves on both treatments spent similar amounts of time on both sides of the pen during the preference tests, suggesting that preference (or tolerance) for standing or exploring in the presence of the social companion was not affected by prior social contact.

Somewhat surprisingly, the preference of calves for social feeding was similar in both tests, despite greater competition for feed in test 2 (i.e., providing one feed bucket on the social side). In comparison, preference tests for social feeding conducted with adult cows demonstrate that submissive cows would rather feed alone than with a more dominant individual, even when feeding alone means compromising the quality of food accessed (Rioja-Lang et al., 2009). Furthermore, Rioja-Lang et al. (2012) reported that when cows were offered the choice of consuming high-palatability food next to a dominant cow or low-palatability food alone, cows did not exhibit a clear preference for consuming the high-palatability food, even when provided ample space at the feeder next to the dominant cow (e.g., 0.75 $\mathrm{m}$ per cow space allowance). It is likely that differences in social feeding preference relate to the social relationship between test animals. Whereas Rioja-Lang et al. (2009, 2012) conducted preference tests with pairs of cows that differed in dominance hierarchy (based on previously observed competitive interactions), preference tests in the present study were conducted with pen mates, reared together from birth, which allows for social bonding (Færevik et al., 2007). Furthermore, we previously found that there was a high degree of synchronized feeding in calves even when they were pro- 
vided limited feeding spaces and displaced each other frequently (Miller-Cushon et al., 2014), suggesting that calves may prefer social feeding with a pen mate even when facing competition. In further research, it may be interesting to assess the preference for social feeding in the presence of an unfamiliar calf, as Veissier et al. (1994) found that calves raised individually had more frequent agonistic interactions upon grouping with unfamiliar calves than calves previously housed socially.

\section{CONCLUSIONS}

These results suggest that social contact before weaning encourages more frequent meals of both milk and solid feed, encourages greater solid-feed DMI before weaning, and has persistent effects on meal characteristics after weaning. When paired within treatment after weaning, calves previously housed in pairs had more frequent, smaller meals than calves raised individually. Differences in feeding behavior arising from early social environment persisted until the conclusion of the study at $5 \mathrm{wk}$ after weaning. Although the frequency of synchronized meals was not influenced by previous social housing, the results of a preference test suggest that calves raised in pairs choose to spend more time feeding with a social companion than calves raised individually. Thus, the effects of early social environment on meal patterning may relate to differences in how calves respond to social pressure or preference for social feeding.

\section{ACKNOWLEDGMENTS}

We thank the staff and students at the University of Guelph (Canada), Kemptville Campus, Dairy Education and Research Centre. In particular, we thank Megan Bruce and Morgan Overvest of the University of Guelph, Kemptville Campus, for their technical assistance. This project was funded through a NSERC Discovery Grant (T. J. DeVries) and an Ontario Ministry of Agriculture, Food and Rural Affairs (OMAFRA)/ University of Guelph Production Systems research grant and supported by Nutreco Canada Inc. (Guelph, Ontario, Canada). This project was also supported through contributions from the Canadian Foundation for Innovation (CFI) and the Ontario Research Fund.

\section{REFERENCES}

Albright, J. L. 1993. Feeding behavior of dairy cattle. J. Dairy Sci. $76: 485-498$.

Anderson, N. G. 2013. Group housing and feeding of milk-fed calves: Moving closer to nature's way. Ontario Ministry of Agriculture, Food, and Rural Affairs. Accessed Feb. 1, 2014. http://www. omafra.gov.on.ca/english/livestock/dairy/facts/grouphousing. htm.
AOAC International. 2000. Official Methods of Analysis. Vol. I. 17th ed. AOAC Int., Arlington, VA.

CCAC (Canadian Council on Animal Care). 2009. CCAC Guidelines on the Care and Use of Farm Animals in Research, Teaching and Testing. Canadian Counc. Anim. Care, Ottawa, ON, Canada.

Chua, B., E. Coenen, J. van Delen, and D. M. Weary. 2002. Effects of pair versus individual housing on the behavior and performance of dairy calves. J. Dairy Sci. 85:360-364.

Costa, J. H. C., R. K. Meagher, M. A. G. von Keyserlingk, and D. M. Weary. 2015. Early pair housing increases solid feed intake and weight gains in dairy calves. J. Dairy Sci. 98:6381-6386.

De Paula Vieira, A., A. M. de Passillé, and D. M. Weary. 2012a. Effects of the early social environment on behavioral responses of dairy calves to novel events. J. Dairy Sci. 95:5149-5155.

De Paula Vieira, A., A. M. de Passillé, and D. M. Weary. 2012b. Presence of an older weaned companion influences feeding behavior and improves performance of dairy calves before and after weaning from milk. J. Dairy Sci. 95:3218-3224.

De Paula Vieira, A., M. A. G. von Keyserlingk, and D. M. Weary. 2010. Effects of pair versus single housing on performance and behavior of dairy calves before and after weaning from milk. J. Dairy Sci. 93:3079-3085.

DeVries, T. J., and M. A. G. von Keyserlingk. 2009. Competition for feed affects the feeding behavior of growing dairy heifers. J. Dairy Sci. 92:3922-3929.

DeVries, T. J., M. A. G. von Keyserlingk, D. M. Weary, and K. A. Beauchemin. 2003. Measuring the feeding behavior of lactating dairy cows in early to peak lactation. J. Dairy Sci. 86:3354-3361.

Duve, L. R., and M. B. Jensen. 2011. The level of social contact affects social behaviour in pre-weaned dairy calves. Appl. Anim. Behav. Sci. 135:34-43.

Duve, L. R., and M. B. Jensen. 2012. Social behavior of young dairy calves housed with limited or full social contact with a peer. J. Dairy Sci. 95:5936-5945.

Duve, L. R., D. M. Weary, U. Halekoh, and M. B. Jensen. 2012. The effects of social contact and milk allowance on responses to handling, play, and social behavior in young dairy calves. J. Dairy Sci. 95:6571-6581.

Færevik, G., I. L. Andersen, M. B. Jensen, and K. E. Bøe. 2007. Increased group size reduces conflicts and strengthens the preference for familiar group mates after regrouping of weaned dairy calves (Bos taurus). Appl. Anim. Behav. Sci. 108:215-228.

Galef, B. G., and K. N. Laland. 2005. Social learning in animals: Empirical studies and theoretical models. Bioscience 55:489-499.

Jensen, M. B., L. R. Duve, and D. M. Weary. 2015. Pair housing and enhanced milk allowance increase play behavior and improve performance in dairy calves. J. Dairy Sci. 98:2568-2575.

Jensen, M. B., K. S. Vestergaard, C. C. Krohn, and L. Munksgaard. 1997. Effect of single versus group housing and space allowance on responses of calves during open-field tests. Appl. Anim. Behav. Sci. 54:109-121.

Launchbaugh, K. L., and L. D. Howery. 2005. Understanding landscape use patterns of livestock as a consequence of foraging behavior. Rangeland Ecol. Manag. 58:99-108.

MacDonald, P. D. M., and P. E. J. Green. 1988. User's Guide to Program MIX: An Interactive Program for Fitting Mixtures of Distributions. Release 2.3, January 1988. Ichthus Data Syst., Hamilton, Ontario, Canada.

Miller-Cushon, E. K., R. Bergeron, K. E. Leslie, and T. J. DeVries. 2013. Effect of milk feeding level on development of feeding behavior in dairy calves. J. Dairy Sci. 96:551-564.

Miller-Cushon, E. K., R. Bergeron, K. E. Leslie, G. J. Mason, and T. J. DeVries. 2014. Competition during the milk-feeding stage influences the development of feeding behavior of pair-housed dairy calves. J. Dairy Sci. 97:6450-6462.

Miller-Cushon, E. K., and T. J. DeVries. 2011. Technical note: Validation of methodology for characterization of feeding behavior of dairy calves. J. Dairy Sci. 94:6103-6110.

Morris, T. R. 1999. Experimental Design and Analysis in Animal Sciences. CABI Publ., New York, NY. 
Nicol, C. J. 1995. The social transmission of information and behaviour. Appl. Anim. Behav. Sci. 44:79-98.

NRC. 2001. Nutrient Requirements of Dairy Cattle. 7th rev. ed. Natl. Acad. Sci., Washington, DC.

Phillips, C. J. C. 2004. The effects of forage provision and group size on the behavior of calves. J. Dairy Sci. 87:1380-1388.

Proudfoot, K. L., D. M. Veira, D. M. Weary, and M. A. G. von Keyserlingk. 2009. Competition at the feed bunk changes the feeding, standing, and social behavior of transition dairy cows. J. Dairy Sci. 92:3116-3123.

Rioja-Lang, F. C., D. J. Roberts, S. D. Healy, A. B. Lawrence, and M. J. Haskell. 2009. Dairy cows trade-off feed quality with proximity to a dominant individual in Y-maze choice tests. Appl. Anim. Behav. Sci. 117:159-164.

Rioja-Lang, F. C., D. J. Roberts, S. D. Healy, A. B. Lawrence, and M. J. Haskell. 2012. Dairy cow feeding space requirements assessed in a Y-maze choice test. J. Dairy Sci. 95:3954-3960.
SAS Institute Inc. 2012. SAS Version 9.4. SAS Inst. Inc., Cary, NC. Stanton, A. L., D. F. Kelton, S. J. LeBlanc, J. Wormuth, L. K. Fox, and K. E. Leslie. 2013. Effects of tulathromycin on incidence of various diseases and growth of young heifers. J. Am. Vet. Med. Assoc. 243:267-276.

Van Soest, P. J., J. B. Robertson, and B. A. Lew. 1991. Methods for dietary fiber, neutral detergent fiber, and nonstarch polysaccharides in relation to animal nutrition. J. Dairy Sci. 74:3583-3597.

Veissier, I., V. Gesmier, P. Le Neindre, and J. Y. Gautier. 1994. The effects of rearing in individual crates on subsequent social behaviour of veal calves. Appl. Anim. Behav. Sci. 41:199-210.

von Keyserlingk, M. A. G., L. Brusius, and D. M. Weary. 2004. Competition for teats and feeding behavior by group-housed dairy calves. J. Dairy Sci. 87:4190-4194. 